\title{
Tree shrews at the German Primate Center
}

\author{
E. Fuchs \\ German Primate Center, Kellnerweg 4, 37077 Göttingen, Germany \\ Correspondence to: E. Fuchs (efuchs@gwdg.de)
}

Received: 4 August 2015 - Revised: 31 August 2015 - Accepted: 1 September 2015 - Published: 25 September 2015

\begin{abstract}
For many years, Tupaia (family Tupaiidae), most commonly known as tree shrews, have been studied almost exclusively by zoologists resulting in a controversial debate on their taxonomic status among mammals. Today, tree shrews are placed in the order Scandentia; they are valuable, widely accepted and increasingly used model animals as an alternative to rodents and non-human primates in biomedical research. After a brief description on how tree shrews entered science and their taxonomic odyssey, the present article describes the history of the tree shrew (Tupaia belangeri) colony at the German Primate Center and selected aspects of our work with special emphasis on the psychosocial stress model in these animals.
\end{abstract}

\section{History and taxonomic odyssey}

In a comprehensive survey of the family of Tupaiidae Lyon Jr. (1913) provides in the first chapters of his article the following historical summary on the discovery of tree shrews:

The earliest published account of treeshrews is that of Ellis $\left(1780^{1}, 1782^{2}\right)$, one of the surgeons of Captain Cook's expedition. On Tuesday or Wednesday, 25th or 26th of January, 1780, Ellis remarks: "Our sportsmen ... having seen only a few monkeys, squirrels, and a cock and a hen, the latter of which they shot. According to Linnaeus this island is their native place." The island referred to is Pulo Condore, off the coast of Cochin China. The squirrels mentioned in the account are not squirrels, but Tupaias. One of them was evidently shot. A rough but very accurate sketch of the animal was made by Ellis and a Latin diagnosis of it written in his journal. This description of the animal was published by Gray in $1860^{3}$. A reproduction of a

\footnotetext{
${ }^{1}$ Description and colored illustration of Tupaia dissimilis. The description published by Gray (1860), p. 71. A copy of Ellis's drawing is Fig. 1 of this paper.

${ }^{2}$ On p. 340 of Vol. 2 the tree shrews of Pulo Condore are referred to as squirrels.

${ }^{3}$ Original publication of W. Ellis's account of "Sciurus dissimilis" (i.e., Tupaia dissimilis).
}

photograph of Ellis' drawing is here printed. There can be no doubt from Ellis' picture or description that his squirrels were Tupaias (see Fig. 1).

Tupaias as such were first brought to the attention of the world by Diard, a French naturalist, at one time an assistant of Sir Thomas Stamford Raffles, in November, 1820, under the designation of Sorex glis (Diard, 1820 ${ }^{4}$ ).

Six months later, May, 1821, the genus Tupaia was first proposed by Sir Raffles $\left(1821^{5}\right)$, and the species ferruginea and tana described, the latter in the present paper being made the type of a new genus.

Specimens of Tupaias had been seen by Europeans several years earlier, and one even sent to Europe. Geoffroy Saint-Hilaire $\left(1835^{6}\right)$ remarks:

"The discovery of this remarkable group of Insectivores has been attributed to both M. Diard and Sir Raffles. The fact is that it belongs to neither of these celebrated travelers, but to Leschenault de la Tour, who had sent in 1807 to the Museum of Paris an individual of the species which has

\footnotetext{
${ }^{4}$ The first published account of a tree shrew and original description of Sorex glis (= Tupaia glis glis) from Penang.

${ }^{5}$ Original description of the genus Tupaia and species ferruginea and tana; remarks on habits.

${ }^{6}$ Original description of Tupaia belangeri.
} 


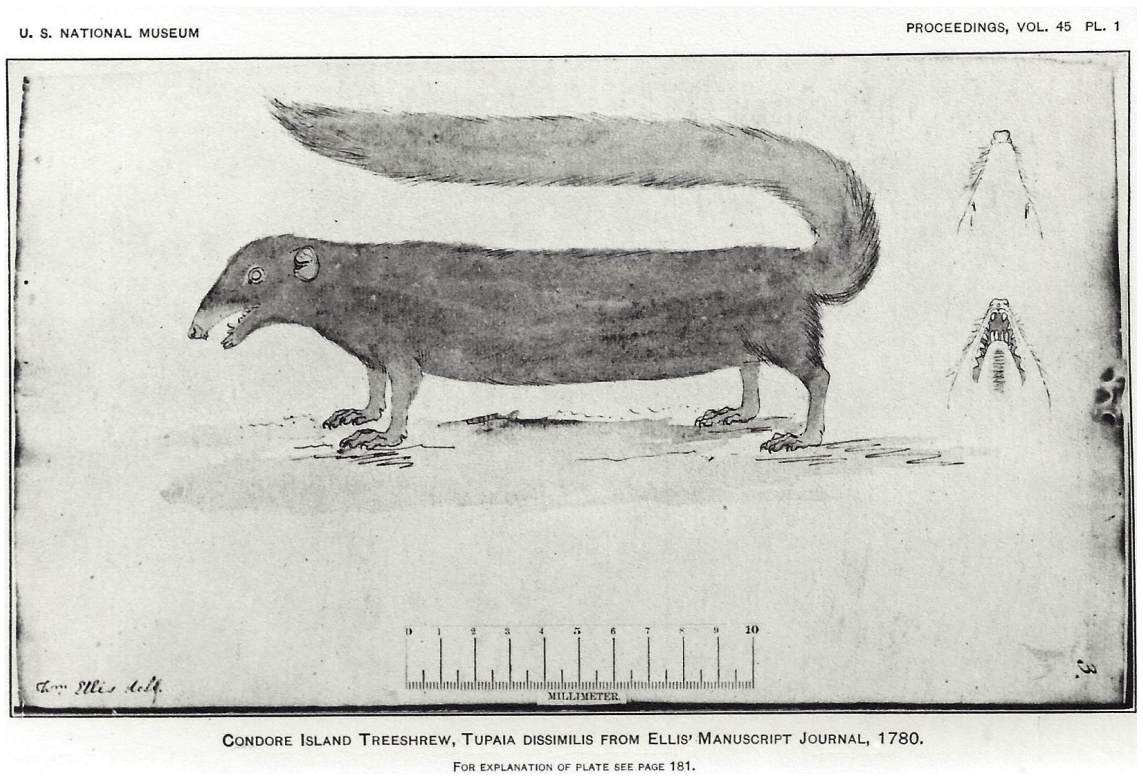

Figure 1. Tupaia dissimilis, Pulo Condore. Reproduction of the original Figure of William Ellis' Sciurus dissimilis, in his natural history journal, written during Captain Cook's third voyage, 1776-1780; now in the British Museum (Natural History). A scale of 100 mm was laid on the page when the photograph was made. Picture taken from Lyon Jr. (1913).

since been called Tupaia javanica. Nevertheless it is only since 1820 that the attention of naturalists has called to Tupaias, and that these animals have really entered the domain of science.

Geoffroy was naturally quite unaware of the existence of Ellis's manuscript notes and drawings. Since Diard's and Raffles's time the group has become better and better known and its geographic range widely extended."

Uncertainties concerning the taxonomic affinities of tree shrews originated with Ellis' description in which tree shrews were designated "squirrels", a confusion that still occasionally persists today. The Malay word tupai is used for both tree shrews and squirrels (Nowak, 1991). In this context it is interesting to mention that Tupaia was the name of a legendary leader of the Polynesian island of Raiatea and a navigator who traveled with Captain Cook's ship Endeavour acting as the expedition's interpreter (http://www.bbc.co.uk/history/british/ empire_seapower/cook_tupaia_maori_01.shtml). Thus it remains a matter of discussion whether the generic name is derived from the Malay word or is a tribute to the Polynesian navigator.

Despite their name, tree shrews have nothing to do with real shrews and most species of tree shrews are semi-arboreal and usually forage on the ground. In general, they all are relatively small, agile and omnivorous animals with a preference for fruits and invertebrates, especially arthropods. Although there are clear differences between tree shrew species, they share a basic common pattern that can be described with ref- erence to the well known Belanger's tree shrew, Tupaia belangeri (Fig. 2). The geographic distribution of tree shrews extends from India to the Philippines and from southern China to Java, Borneo, Sumatra, and Bali. Natural habitats are tropical forests and plantation areas.

For many years, a variety of reports described similarities between tree shrews and primates, and the conclusion that there was a direct phylogenetic relationship between tree shrews and primates was predominantly made by Le Gros Clark (1924), largely on the basis of brain anatomy. His view was confirmed in Simpson's classification of the mammals (Simpson, 1945). In the following years, several authors had doubts about this phylogenetic link and, as a result, excluded tree shrews from primates. An intensive discussion of tree shrews and their phylogenetic relationships is provided by, for example, Luckett (1980), Martin (1990) and Emmons (2000). Today, tree shrews are placed in their own order, Scandentia (see also Knabe and Washausen, 2015). According to recent molecular phylogenetic studies they are placed together with primates and Dermoptera within the clade Euarchonta (Kriegs et al., 2007). In 2008, the Broad Institute provided the first assembly of the genome of $T u$ paia belangeri (http://www.ensembl.org/Tupaia_belangeri/ Info/Index). On the basis of more advanced genome information of the Chinese tree shrew (Tupaia belangeri chinensis), Fan et al. (2013) postulated that tree shrews have a relatively close relationship to non-human primates. Nevertheless, the long-running debate regarding the phylogenetic position of the tree shrew within eutherian mammals seems not fully settled. 


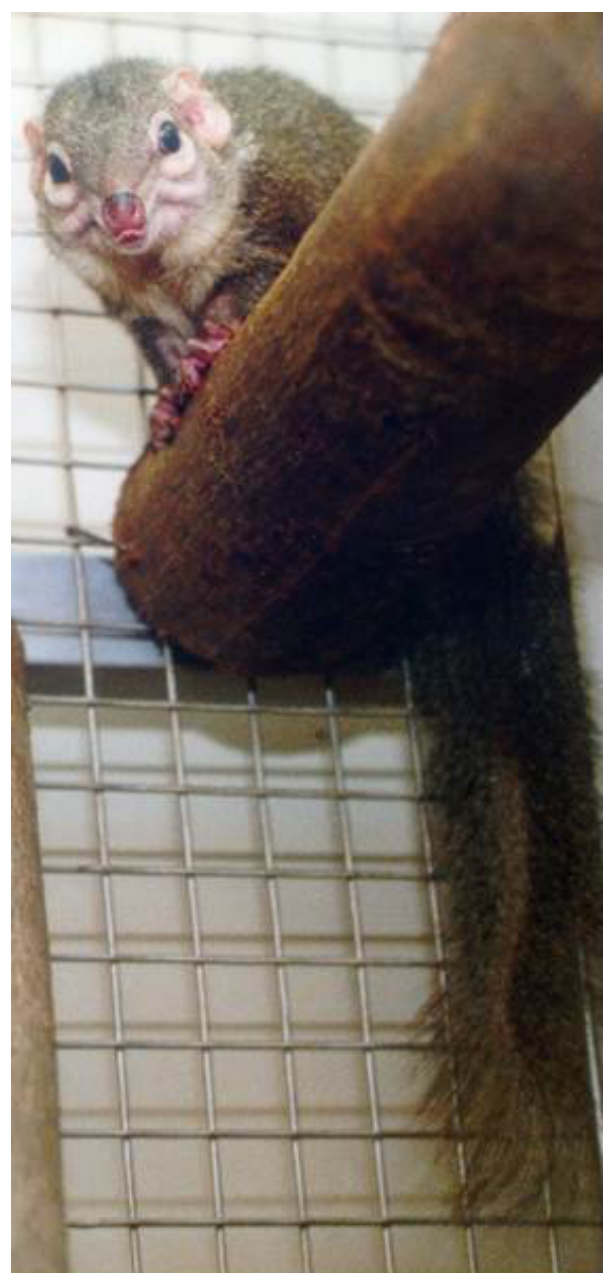

Figure 2. Adult male tree shrew (Tupaia belangeri) from the DPZ colony.

\section{The tree shrew colony at the German Primate Center}

In December 1983, Hans-Jürg Kuhn transferred a group of 18 male and 23 female Tupaia belangeri from the Zoological Institute, University of Munich, to Göttingen. Originally housed in the former Department of Forensic Medicine at the University of Göttingen, more than 50 tree shrews moved in January 1985 to the animal facility of the German Primate Center (DPZ). This was the starting point for nearly 30 years of successful work in the author's group resulting in more than 100 publications on tree shrews.

With substantial support of Hans-Jürg Kuhn and Eckhard W. Heymann, the housing and breeding protocol was optimized with the aim to become independent of imports from Thailand and to generate animals with known background for our own investigations. Routine colony health screening procedures were carried out and veterinary as well as pathological assistance was available. Tree shrews from the DPZ colony experienced relatively few health problems;

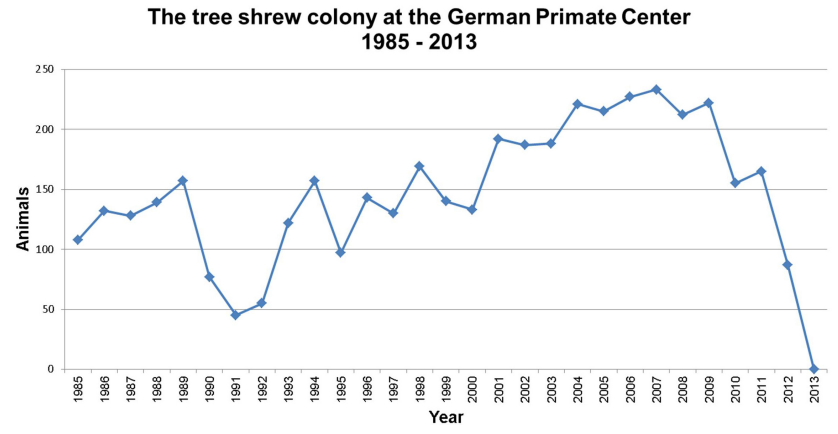

Figure 3. The development of the tree shrew colony of the DPZ from 1985 to 2013.

the most frequent ones are summarized in the contribution by Brack (2015). A detailed description of housing and breeding tree shrews at the DPZ is given by Fuchs and CorbachSöhle (2010).

Parallel to the colony at the DPZ Hans-Jürg Kuhn maintained a back-up colony at the Department of Anatomy, University of Göttingen, until his retirement. From time to time tree shrews from other colonies were introduced - in particular from Elke Zimmermann, now director of the Institute of Zoology, University of Veterinary Medicine Hanover, Germany - to avoid inbreeding. Over the years animals from the tree shrew colony at the DPZ were provided to other research institutes in Germany and Europe.

As shown in Fig. 3, the DPZ colony constantly developed with a maximum of more than 200 animals between 2004 and 2009. With the help of Klaus Nebendahl (at that time head of the animal facilities of the University Medical Center, University of Göttingen) we extended in 2004 the housing capacity mainly for breeding tree shrews at Gut Holtensen, located about $5 \mathrm{~km}$ away from the DPZ. In the processes of closing the Clinical Neurobiology Laboratory at the DPZ and the author's retirement, the tree shrew colony was also closed. Most of the animals were moved to the Department of Behavioral Physiology, Center for Behavior and Neurosciences, University of Groningen, the Netherlands. The history of tree shrews at the DPZ ended on 24 September 2013 with the transfer of a view remaining animals to the Institute of Anatomy, Faculty of Veterinary Medicine, University of Leipzig, Germany.

\section{Tree shrews in laboratory}

Tree shrews have proved to be useful experimental animal in many instances where a small omnivorous non-rodent species is required (e.g., Cao et al., 2003). They can be investigated in many fields of preclinical research such as toxicology and virology, in particular in studies investigating herpes and hepatitis viruses (Hunt, 1993; Zhao et al., 2002; Xu et al., 2007; Amako et al., 2010). Further, various aspects of behavior including learning (Ohl et al., 1998; Nair et al., 

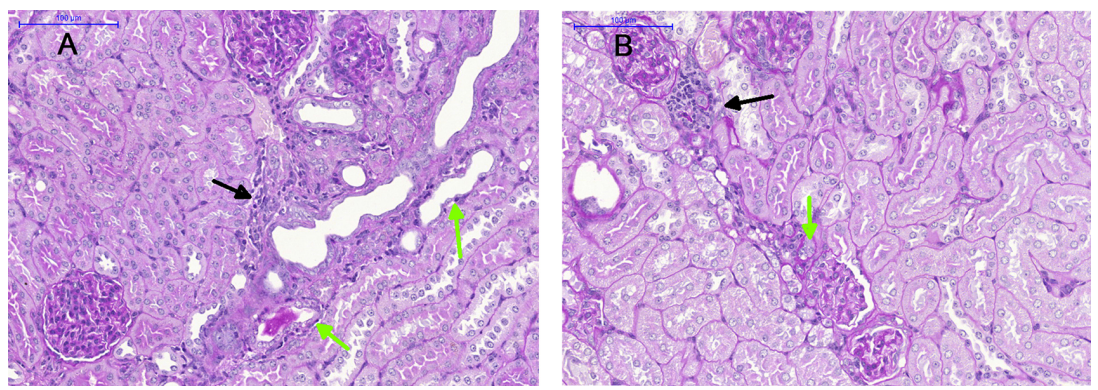

Figure 4. Kidney sections of a control (a) and a stressed (b) male tree shrew. The black arrows indicate inflammatory infiltrating cells, while the green arrows indicate atrophic tubuli. Qualitative analysis did not reveal any indication of stress-induced renal damage. Blue bars represent $100 \mu \mathrm{m}$.

2014), infant development, communication, social structures (e.g., Martin, 1968a, b; Hertenstein et al., 1987; Binz et al., 1990), emotions (Schehka et al., 2007; Schehka and Zimmermann, 2009, 2012) and various neurobiological questions (e.g., Norton et al., 2006; Kaas et al., 2013, and Table 1) including the effects of psychosocial stress (e.g., Fuchs, 2005) can be studied in tree shrews.

Based on a study by von Holst (1972), psychosocially stressed male tree shrews were thought to be a suitable model to study the mechanisms of acute renal failure. However, we (see Fig. 4) and others (Steinhausen et al., 1978) were unable to replicate these results.

A high degree of genetic homology between tree shrews and primates was found for several receptor proteins of neuromodulators (see Fuchs and Flügge, 2002) and the amyloidbeta precursor protein (Pawlik et al., 1999). The 3-4 times longer life span of tree shrews than rodents (Keuker et al., 2005) suggests that tree shrews may be useful for studies focusing on aging-related brain changes (e.g., Michaelis et al., 2001; Yamashita et al., 2012).

\section{The psychosocial stress model}

In their natural habitats male tree shrews defend their territories vigorously against intruding conspecifics (Kawamichi and Kawamichi, 1979). Originally developed by Raab (1971) and later adopted by von Holst (1972) we used this pronounced territoriality (Sorenson, 1974) to establish a naturally occurring challenging situation under experimental control in the laboratory. All animal experimentation was carried out in accordance with the European Council Directives and the German Animal Welfare Acts in force and was approved by the responsible authorities of the federal state of Lower Saxony, Germany.

For the stress exposure we developed the following standard protocol (e.g., Schmelting et al., 2014). In brief, in the first experimental phase (pre-stress) - during which all animals remained undisturbed - body weight and behavior was recorded daily, and morning urine samples were collected daily by a slight massage of the hypogastrium. After this pe-

\section{The psychosocial stress model in male tree shrews}

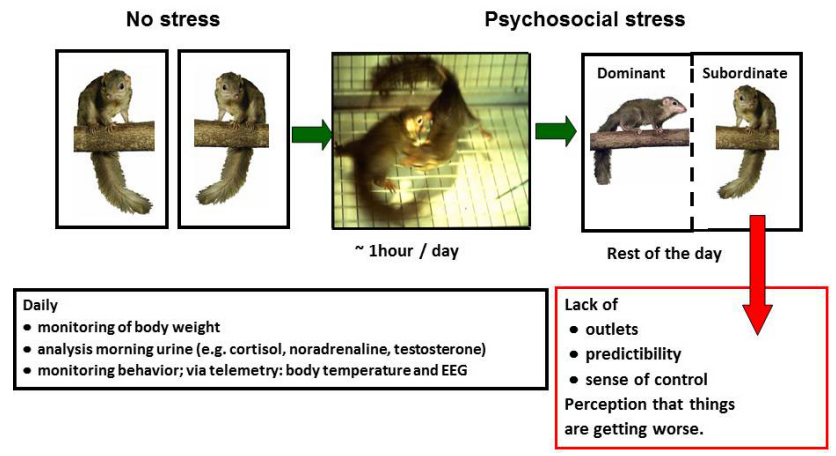

Figure 5. Schematic presentation of the psychosocial stress model in male tree shrews. For the subordinate male the situation is characterized by a lack of outlets, no predictability and no sense of control.

riod animals were divided into two groups: the non-stressed control and stressed group. The animals from the stress group were exposed to daily psychosocial conflict, while the nonstressed controls remained undisturbed elsewhere in the animal facility. Psychosocial stress was induced by introducing a inexperienced animal into the cage of another male that had already become dominant in previous confrontations with a subordinate. During confrontation the animals were closely monitored; in case of severe fights, the animals were separated immediately by a wire mesh barrier to avoid physical injuries. Thus, direct physical contact was only allowed for approximately $1 \mathrm{~h}$ every day. During the stress phase, the wire mesh barrier was removed daily at random time points to enhance unpredictability. Using this procedure, the subordinate male was protected from repeated attacks but was constantly exposed to olfactory, visual, and acoustic cues from the dominant male (Fig. 5). To exclude the effects of individual differences in the intensity of attacks by the dominant male and to avoid habituation, the subordinate animal was confronted daily with another dominant male according to a Latin square design. 
Table 1. Summary of stress-induced changes in male tree shrews. With modifications from Fuchs and Flügge (2002).

\begin{tabular}{|c|c|}
\hline & Effects of chronic psychosocial stress \\
\hline \multicolumn{2}{|c|}{ Physiological and neuroendocrine parameters } \\
\hline Body weight & Decreased (Fuchs et al., 1993) \\
\hline HPA axis & $\begin{array}{l}\text { Non-adapting increase of urinary cortisol - no suppression by dexamethasone } \\
\text { (Kramer et al., 1999; Kohlhause et al., 2011) and enlarged adrenal glands (Fuchs } \\
\text { et al., 1993) }\end{array}$ \\
\hline Sympathetic nervous system & Increased urinary adrenaline and noradrenaline (Fuchs et al., 1993) \\
\hline Gonadal system & $\begin{array}{l}\text { Decreased testosterone (Kohlhause et al., 2011) and testes weight (Fischer et } \\
\text { al., 1985) }\end{array}$ \\
\hline Sleep & Reduced slow wave sleep, more/longer awake phases (Fuchs and Flügge, 2002) \\
\hline Circadian rhythm & $\begin{array}{l}\text { Elevated core body temperature (Kohlhause et al., 2011; Schmelting et } \\
\text { al., 2014), heart rate (Stöhr, 1986) and oxygen consumption (Fuchs and } \\
\text { Kleinknecht, 1986) during resting period }\end{array}$ \\
\hline \multicolumn{2}{|l|}{ Behavior and memory } \\
\hline General motor activity & Reduced (Kramer et al., 1999; Schmelting et al., 2014) \\
\hline Self-grooming & Reduced (Kramer et al., 1999) \\
\hline Scent marking activity & Reduced (Kramer et al., 1999) \\
\hline Food and water intake & Reduced (Kramer et al., 1999) \\
\hline Hippocampus-mediated memory & Persistently impaired (Ohl and Fuchs, 1999) \\
\hline \multicolumn{2}{|c|}{ Structural and functional changes in the brain } \\
\hline Neurogenesis in the dentate gyrus & $\begin{array}{l}\text { Inhibition of the proliferation of granule precursor cells (Gould et al., 1997; } \\
\text { Czéh et al., 2001) }\end{array}$ \\
\hline Retraction of dendrites & $\begin{array}{l}\text { Retraction of apical dendrites of pyramidal neurons in the CA3 of the hippocam- } \\
\text { pus (Magariños et al., 1996) }\end{array}$ \\
\hline Volume of the hippocampal formation & Volume reduced by approximately $10 \%$ (Ohl et al., 2000; Czéh et al., 2001) \\
\hline Brain metabolites & $\begin{array}{l}\text { Significantly decreased in vivo concentrations of } N \text {-acetyl-aspartate, crea- } \\
\text { tine/phosphocreatine, and choline-containing compounds (Czéh et al., 2001) }\end{array}$ \\
\hline $\begin{array}{l}\text { Hippocampal gluco- and } \\
\text { mineralocorticoid receptors }\end{array}$ & $\begin{array}{l}\text { Downregulation of glucocorticoid receptors; regional up- and downregulation } \\
\text { of mineralocorticoid receptors (Meyer et al., 2001) }\end{array}$ \\
\hline $\mathrm{CRH}$ receptors & $\begin{array}{l}\text { Downregulation of binding sites for }{ }^{125} \text { I-ovine corticotropin releasing hormone } \\
\text { (CRH) in anterior pituitary, dentate gyrus, CA } 1 \text { and CA } 3 \text { of the hippocampus, } \\
\text { area } 17 \text {, superior colliculus; upregulation of binding sites for }{ }^{125} \text { I-ovine CRH } \\
\text { in cortical regions, amygdala, choroid plexus (Fuchs and Flügge, 1995) }\end{array}$ \\
\hline $5-\mathrm{HT}_{1 A}$ receptors & $\begin{array}{l}\text { Gradual downregulation of heteroreceptors in hippocampus and cortical re- } \\
\text { gions; fast renormalization after stress or hormonal replacement (Flügge, 1995; } \\
\text { Flügge et al., 1998) }\end{array}$ \\
\hline Alpha 2 -adrenoceptors & $\begin{array}{l}\text { Downregulation in brain regions involved in autonomic functions (Flügge, } \\
\text { 1996; Flügge et al., 1992; Meyer et al., 2000) }\end{array}$ \\
\hline Beta $_{1}$-adrenoceptors & $\begin{array}{l}\text { After } 4 \text { weeks downregulation in hippocampus and parietal cortex; transient } \\
\text { effects in prefrontal cortex, olfactory area, and pulvinar nucleus (Flügge et al., } \\
\text { 1997) }\end{array}$ \\
\hline Beta2-adrenoceptors & $\begin{array}{l}\text { After } 4 \text { weeks upregulation in pulvinar nucleus; transient effects in prefrontal } \\
\text { cortex (Flügge et al., 1997) }\end{array}$ \\
\hline
\end{tabular}

Subordinate tree shrews show significant changes in behavior, physiology, endocrine function and neuronal activity. They lose body weight and have reduced locomotor activity; their sleeping pattern is characterized by an increasing number of early morning waking episodes, and their circadian rhythm is profoundly disturbed. Analysis of endocrine function in subordinates reveals consistently elevated concentrations of the adrenocortical hormone cortisol, en- larged adrenals, increased concentrations of noradrenalin and adrenalin indicating enhanced sympathetic activity and reduced gonadal function (see Table 1). Since the distinct, stress-induced behavioral, physiological, and central nervous system alterations in subordinate animals result exclusively from cognitive interpretation of the continuous visual presence of the dominant conspecific (Raab and Storz, 1976; Raab and Ostwald, 1980), this paradigm has been termed 


\section{Experimental design of the antidepressant drug studies}

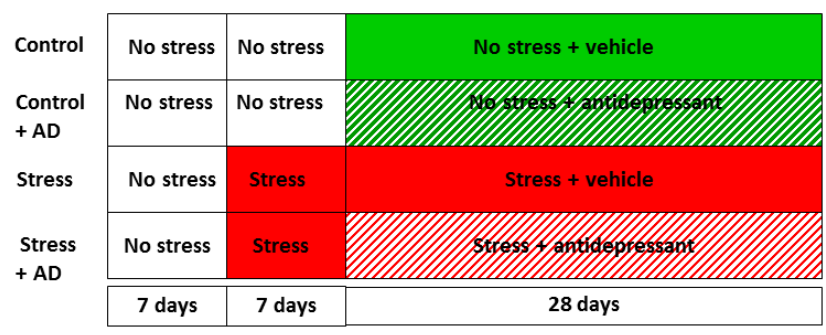

Figure 6. Schematic presentation of the experimental design of antidepressant drug studies. Control: no stress; AD: antidepressant.

"psychosocial stress". Importantly, the bio-behavioral responses observed in subordinate tree shrews are similar to the signs and symptoms seen in depressed patients. Thus, the chronic psychosocial stress model in tree shrews has clear "face validity" (Willner, 1984) for human depression (for review see Fuchs, 2005).

To investigate whether the tree shrew model also possesses predictive validity (Willner, 1984), we treated subordinate shrews with established and as well as potential antidepressants such as clomipramine, fluoxetine, tianeptine, agomelatine and different NK1 receptor antagonists. It is important to note that (i) we determined and used the appropriate dose of the antidepressants necessary to reach therapeutically relevant serum concentrations (e.g., Czéh et al., 2006); (ii) the daily oral treatment commenced only when the stressinduced behavioral and endocrine changes became obvious; (iii) the psychosocial stress situation was continued during the treatment; and (iv) the therapeutic action of the drug was assessed for the clinically appropriate period of time of 4 weeks (Fig. 6).

Using this approach we found in subordinate animals a time-dependent restoration of endocrine, behavioral and central nervous parameters such as neurogenesis, hippocampal volume and brain metabolism (Czéh et al., 2001, 2005; Fuchs et al., 1996; van der Hart et al., 2002, 2005; Schmelting et al., 2014). In contrast, the anxiolytic diazepam was ineffective in this experimental setting (van Kampen et al., 2000).

Despite its obvious attractiveness there are, as in other stress models, limitations of the tree shrew psychosocial stress paradigm. One major limitation is housing and breeding, which are space and time consuming, and therefore only a limited number of experimental animals is available. Obviously, this constraint explains why only a few other laboratories are capable of using this model. One is at the Kunming Institute of Zoology, Chinese Academy of Sciences, China, performing intensive research on Tupaia belangeri chinensis a close relative of Tupaia belangeri. Using a similar stress model Wang et al. (2013) could confirm our finding with clomipramine showing that depression-like core symptoms in subordinate tree shrews could be reversed by a chronic treatment with this established tricyclic antidepressant.

\section{Conclusion}

The chronic psychosocial stress paradigm in tree shrews characterized and validated at the DPZ can be regarded a "homologous model" of depression. It mimics several aspects of the human disease in the subordinate animal; the state of the animal is induced by similar stimuli that cause the condition in humans, and pharmacotherapy, which is efficacious in human illness, is effective in the model. The advantage of such a homologous model is that it can probably contribute to the understanding of the pathophysiology of depression and it might also lead to the development of new effective drugs for treatment of the illness. Although more research is required to further validate the tree shrew model, it provides an adequate and interesting non-rodent experimental paradigm for preclinical research on depression.

The work on tree shrews conducted for nearly 3 decades at the German Primate Center would not have been possible without the encouragement of Hans-Jürg Kuhn, the neverending great enthusiasm of all members of the research group and the substantial support provided by many collaborators, grant agencies and industrial partners.

Edited by: E. W. Heymann

Reviewed by: F.-J. Kaup and E. Zimmermann

\section{References}

Amako, Y., Tsukiyama-Kohara, K., Katsume, A., Hirata, Y., Sekiguchi, S., Tobita, Y., Hayashi, Y., Hishima, T., Funata, N., Yonekawa, H., and Kohara, M.: Pathogenesis of hepatitis C virus infection in Tupaia belangeri, J. Virol., 84, 303-311, 2010.

Binz, H., Zurhorst, C., Zimmermann, E., and Rahmann, H.: Neuronal substrates involved in processing of communicative acoustic signals in tree shrews: a 2-deoxyglucose study, Neurosci. Lett., 112, 25-30, 1990.

Brack, M.: The Department of Pathology at the German Primate Center from 1973 to 1999, Primate Biol., 2, 81-87, doi:10.5194/pb-2-81-2015, 2015.

Cao, J., Yang, E. B., Su, J. J., Li, Y., and Chow, P.: The tree shrews: Adjuncts and alternatives to primates as models for biomedical research, J. Med. Primatol., 32, 123-130, 2003.

Czéh, B., Michaelis, T., Watanabe, T., Frahm, J., de Biurrun, G., van Kampen, M., Bartolomucci, A., and Fuchs, E.: Stress induced changes in cerebral metabolites, hippocampal volume, and cell proliferation are prevented by antidepressant treatment with tianeptine, P. Natl. Acad. Sci. USA, 98, 12796-12801, 2001.

Czéh, B., Pudovkina, O., van der Hart, M. G., Simon, M., Heilbronner, U., Michaelis, T., Watanabe, T., Frahm, J., and Fuchs, E.: Examining SLV-323, a novel NK1 receptor antagonist, in a chronic psychosocial stress model for depression, Psychopharmacology (Berl), 180, 548-557, 2005. 
Czéh, B., Simon, M., Schmelting, B., Hiemke, C., and Fuchs, E.: Astroglial plasticity in the hippocampus after chronic psychosocial stress and concomitant fluoxetine treatment, Neuropsychopharmacology, 31, 1616-1626, 2006.

Diard, P.-M.: Report of a meeting of the Asiatic Society of Bengal for March 10, 1820, Asiat. Journ. Month. Reg., 10, 477-478, 1820.

Ellis, W.: Manuscript Journal and drawings of animals observed Capt. Cook's third voyage, Library of British Museum (Natural History), 1780.

Ellis, W.: Voyage of Capt. Cook and Capt. Clerke in Ships Resolution and Discovery, 1776, 1777, 1778, 1779, and 1780, 1782.

Emmons, L. H.: Tupai: A field study of Bornean treeshrews, University of California Press, Berkeley, 2000.

Fan, Y., Huang, Z. Y., Cao, C. C., Chen, C. S., Chen, Y. X., Fan, D. D., He, J., Hou, H. L., Hu, L., Hu, X. T., Jiang, X. T., Lai, R., Lang, Y. S., Liang, B., Liao, S. G., Mu, D., Ma, Y. Y., Niu, Y. Y., Sun, X. Q., Xia, J. Q., Xiao, J., Xiong, Z. Q., Xu, L., Yang, L., Zhang, Y., Zhao, W., Zhao, X. D., Zheng, Y. T., Zhou, J. M., Zhu, Y. B., Zhang, G. J., Wang, J., and Yao, Y. G.: Genome of the Chinese tree shrew, Nat. Commun., 4, 1426, doi:10.1038/ncomms2416, 2013.

Fischer, H. D., Heinzeller, T., and Raab, A.: Gonadal response to psychosocial stress in male tree shrews (Tupaia belangeri) morphometry of testis, epididymis and prostate, Andrologia, 17, 262-275, 1985.

Flügge, G.: Dynamics of central nervous 5-HT1A-receptors under psychosocial stress, J. Neurosci., 15, 7132-7140, 1995.

Flügge, G.: Alterations in the central nervous alpha 2-adrenoceptor system under chronic psychosocial stress, Neuroscience, 75, 187-196, 1996.

Flügge, G., Ahrens, O., and Fuchs, E.: Beta-adrenoceptors in the tree shrew brain. II. Time-dependent effects of chronic psychosocial stress on [125I]iodocyanopindolol bindings sites, Cell. Mol. Neurobiol., 17, 417-432, 1997.

Flügge, G., Jöhren, O., and Fuchs, E.: [3H]Rauwolscine binding sites in the brains of male tree shrews are related to social status, Brain Res., 597, 131-137, 1992.

Flügge, G., Kramer, M., Rensing, S., and Fuchs, E.: 5HT1Areceptors and behaviour under chronic stress: selective counteraction by testosterone, Eur. J. Neurosci., 10, 2685-2693, 1998.

Fuchs, E.: Social stress in tree shrews as an animal model of depression: an example of a behavioral model of a CNS disorder, CNS Spectr., 10, 182-190, 2005.

Fuchs, E. and Corbach-Söhle, S.: Tree shrews, in: The UFAW Handbook on the care and management of laboratory animals and other research animals, edited by: Hubrecht, R. and Kirkwood, J., Wiley-Blackwell, Chichester, 262-275, 2010.

Fuchs, E. and Flügge, G.: Modulation of binding sites for corticotropin-releasing hormone by chronic psychosocial stress, Psychoneuroendocrinology, 20, 33-51, 1995.

Fuchs, E. and Flügge, G.: Social stress in tree shrews: effects on physiology, brain function, and behavior of subordinate individuals, Pharmacol. Biochem. Be., 73, 247-258, 2002.

Fuchs, E. and Kleinknecht, S.: The influence of chronic social confrontation on oxygen consumption of Tupaia belangeri under resting conditions, Z. Säugetierkunde, 51, 55-57, 1986.
Fuchs, E., Jöhren, O., and Flügge, G.: Psychosocial conflict in the tree shrew: effects on sympathoadrenal activity and blood pressure, Psychoneuroendocrinology, 18, 557-565, 1993.

Fuchs, E., Kramer, M., Hermes, B., Netter, P., and Hiemke, C.: Psychosocial stress in tree shrews: clomipramine counteracts behavioral and endocrine changes, Pharmacol. Biochem. Be., 54, 219 228, 1996.

Geoffroy Saint-Hilaire, I.: In Belanger, Voyage aux IndesOrientales, Zoologie, 103-107, 1835.

Gould, E., McEwen, B. S., Tanapat, P., Galea, L. A., and Fuchs, E.: Neurogenesis in the dentate gyrus of the adult tree shrew is regulated by psychosocial stress and NMDA receptor activation, J. Neurosci., 17, 2492-2498, 1997.

Gray, J. E.: Early notice of the Tupaia (sic) found in Pulo Condore, Ann. Mag. Nat. Hist., 5, p. 71, 1860.

Hertenstein, B., Zimmermann, E., and Rahmann, H.: Zur Reproduktion und onogenetischen Entwicklung von Spitzhörnchen, Zeitschrift des Kölner Zoo, 30, 119-133, 1987.

Hunt, R. D.: Herpesviruses of primates: An introduction, in: Nonhuman Primates, edited by: Jones, T. C., Mohr, U., and Hunt, R. D., Springer-Verlag, Berlin, 74-78, 1993.

Kaas, J. H., Gharbawie, O. A., and Stepniewska, I.: Cortical networks for ethologically relevant behaviors in primates, Am. J. Primatol., 75, 407-414, 2013.

Kawamichi, T. and Kawamichi, M.: Spatial organization and territory of tree shrews (Tupaia glis), Anim Behav., 27, 331-393, 1979.

Keuker, J. I. H., Keijser, J. N., Nyakas, C., Luiten, P. G. M., and Fuchs, E.: Aging is accompanied by a subfield-specific reduction of serotonergic fibers in the tree shrew hippocampal formation, J. Chem. Neuroanat., 30, 221-229, 2005.

Knabe, W. and Washausen, S.: Early development of the nervous system of the eutherian Tupaia belangeri, Primate Biol., 2, 25 56, doi:10.5194/pb-2-25-2015, 2015.

Kohlhause, S., Hoffmann, K., Schlumbohm, C., Fuchs, E., and Flügge, G.: Nocturnal hyperthermia induced by social stress in male tree shrews: relation to low testosterone and effects of age, Physiol. Behav., 104, 786-795, 2011.

Kramer, M., Hiemke, C., and Fuchs, E.: Chronic psychosocial stress and antidepressant treatment in tree shrews: timedependent behavioral and endocrine effects, Neurosci. Biobehav. R., 23, $937-$ 947, 1999.

Kriegs, J. O., Churakov, G., Jurka, J., Brosius, J., and Schmitz, J.: Evolutionary history of 7SL RNA-derived SINEs in Supraprimates, Trends Genet., 23, 158-161, 2007.

Le Gros Clark, W. E.: On the brain of the tree shrew (Tupaia minor), P. Zool. Soc. Lond., 1053-1074, 1924.

Luckett, W. P.: Comparative biology and evolutionary relationships of tree shrews, Plenum Press, New York and London, 1980.

Lyon Jr., M. W.: Treeshrews: An account of the mammalian family tupaiide, Proc. U.S. Nat. Museum, 45, 1-188, 1913.

Magariños, A. M., McEwen, B. S., Flügge, G., and Fuchs, E.: Chronic psychosocial stress causes apical dendritic atrophy of hippocampal CA3 pyramidal neurons in subordinate tree shrews, J. Neurosci., 16, 3534-3540, 1996.

Martin, R. D.: Reproduction and ontogeny of tree-shrews (Tupaia belangeri), with reference to their general behaviour and taxomonic relationships, Z. Tierpsychologie, 25, 409-495, 1968a. 
Martin, R. D.: Reproduction and ontogeny in tree-shrews (Tupaia belangeri), with reference to their general behaviour and taxonomic relationships, Z. Tierpsychologie, 25, 505-532, $1968 \mathrm{~b}$.

Martin, R. D.: Primate origins and evolution, Chapman \& Hall, London, 1990.

Meyer, H., Palchaudhuri, M., Scheinin, M., and Flügge, G.: Regulation of alpha(2A)-adrenoceptor expression by chronic stress in neurons of the brain stem, Brain Res., 880, 147-158, 2000.

Meyer, U., van Kampen, M., Isovich, E., Flügge, G., and Fuchs, E.: Chronic psychosocial stress regulates the expression of both GR and MR mRNA in the hippocampal formation of tree shrews, Hippocampus, 11, 329-336, 2001.

Michaelis, T., de Biurrun, G., Watanabe, T., Frahm, J., Ohl, F., and Fuchs, E.: Gender-specific alterations of cerebral metabolites with aging and cortisol treatment, J. Psychiat. Res., 35, 231-237, 2001.

Nair, J., Topka, M., Khani, A., Isenschmid, M., and Rainer, G.: Tree shrews (Tupaia belangeri) exhibit novelty preference in the novel location memory task with 24-h retention periods, Front. Psychol., 14, 303, doi:10.3389/fpsyg.2014.00303, 2014.

Norton, T. T., Amedo, A. O., and Siegwart Jr., J. T.: Darkness causes myopia in visually experienced tree shrews, Invest. Ophth. Visual, 47, 4700-4707, 2006.

Nowak, R. M.: Walker's mammals of the world, John Hopkins University Press, Baltimore, Vol. I, p. 395, 1991.

Ohl, F. and Fuchs, E.: Differential effects of chronic stress on memory processes in the tree shrew, Cog. Brain Res., 7, 379-387, 1999.

Ohl, F., Oitzl, M. S., and Fuchs, E.: Assessing cognitive functions in tree shrews: Visuo-spatial and spatial learning in the home cage, J. Neurosci. Meth., 81, 35-40, 1998.

Ohl, F., Michaelis, T., Vollmann-Honsdorf, G. K., Kirschbaum, C., and Fuchs E.: Effect of chronic psychosocial stress and longterm cortisol treatment on hippocampus-mediated memory and hippocampal volume: a pilot-study in tree shrews, Psychoneuroendocrinology, 25, 357-363, 2000.

Pawlik, M., Fuchs, E., Walker, L. C., and Levy, E.: Primate sequence of amyloid-b protein in tree shrew that do not develop cerebral amyloid deposition, Neurobiol. Aging, 20, 47-51, 1999.

Raab, A.: Der Serotoninstoffwechsel in einzelnen Hirnteilen von Tupaia (Tupaia belangeri) bei soziopsychischen Stress, Z. Vergl. Physiol., 72, 54-66, 1971.

Raab, A. and Oswald, R.: Coping with social conflict: impact on the activity of tyrosine hydroxylase in the limbic system and in the adrenals, Physiol. Behav., 24, 387-394, 1980.

Raab, A. and Storz, H.: A long term study on the impact of sociopsychic stress in tree-shrews (Tupaia belangeri) on central and peripheral tyrosine hydroxylase activity, J. Comp. Physiol., 108, 115-131, 1976.

Schehka, S. and Zimmermann E.: Acoustic features to arousal and identity in disturbance calls of tree shrews (Tupaia belangeri), Behav. Brain Res., 203, 223-231, 2009.

Schehka, S. and Zimmermann, E.: Affect intensity in voice recognized by tree shrews (Tupaia belangeri), Emotion, 12, 632-639, 2012.

Schehka, S., Esser, K. H., and Zimmermann, E.: Acoustical expression of arousal in conflict situations in tree shrews (Tupaia belangeri), J. Comp. Physiol. A, 193, 845-852, 2007.
Schmelting, B., Corbach-Söhle, S., Kohlhause, S., Schlumbohm, C., Flügge, G., and Fuchs, E.: Agomelatine in the tree shrew model of depression: effects on stress-induced nocturnal hyperthermia and hormonal status, Eur. Neuropsychopharm., 24, 437$447,2014$.

Simpson, G. C.: The principles of classification and a classification of mammals, Bull. Am. Mus. Natl. History, 85, 1-350, 1945.

Sir Raffles, T. S.: Description catalogue of a zoological collection made on the account of the Honourable East India Company, in the Island of Sumatra und its vicinity, etc., Trans. Linn. Soc. London, 13, 239-274, 1821.

Sorenson, M. W.: A review of aggressive behavior in the tree shrew, in: Primate aggression, territoriality, and xenophobia, edited by: Holloway, R. L., Academic Press, New York and London, 13-30, 1974.

Steinhausen, M., Thederan, H., Nolinski, D., Dallenbach, F. D., and Schwaier, A.: Further evidence of tubular blockage after acute ischemic renal failure in Tupaia belangeri and rats, Virchows Arch. A, 381, 13-34, 1978.

Stöhr, W.: Heart rate of tree shrews and its persistent modification by social contact, in: Biological and psychological factors in cardiovascular disease, edited by: Schmidt, T. H., Dembrowski, T. M., and Blümchen, G., Springer Verlag: Berlin, Heidelberg, 491499, 1986.

van der Hart, M. G., Czéh, B., de Biurrun, G., Michaelis, T., Watanabe, T., Natt, O., Frahm, J., and Fuchs, E.: Substance P receptor antagonist and clomipramine prevent stress-induced alterations in cerebral metabolites, cytogenesis in the dentate gyrus and hippocampal volume, Mol. Psychiatry, 7, 933-941, 2002.

van der Hart, M. G., de Biurrun, G., Czéh, B., Rupniak, N. M., den Boer, J. A., and Fuchs, E.: Chronic psychosocial stress in tree shrews: effect of the substance P (NK1 receptor) antagonist L760735 and clomipramine on endocrine and behavioral parameters, Psychopharmacology (Berl), 181, 207-216, 2005.

van Kampen, M., Schmitt, U., Hiemke, C., and Fuchs, E.: Diazepam has no beneficial effects on stress-induced behavioural and endocrine changes in male tree shrews, Pharmacol. Biochem. Behav., 65, 539-546, 2000.

von Holst, D.: Renal failure as the cause of death in Tupaia belangeri exposed to persistent social stress, J. Com. Physiol., 78, 236-273, 1972.

Wang, J., Chai, A., Zhou, Q., Lv, L., Wang, L., Yang, Y., and Xu, L.: Chronic clomipramine treatment reverses core symptom of depression in subordinate tree shrews, PLoS One, 8, e80980, doi:10.1371/journal.pone.0080980, 2013.

Willner, P.: The validity of animal models of depression, Psychopharmacology (Berl), 83, 1-16, 1984.

$\mathrm{Xu}, \mathrm{X}$., Chen, H., Cao, X., and Ben, K.: Efficient infection of tree shrew (Tupaia belangeri) with hepatitis $\mathrm{C}$ virus grown in cell culture or from patient plasma, J. Gen. Virol., 88, 2504-2512, 2007.

Yamashita, A., Fuchs, E., Taira, M., Yamamoto, T., and Hayashi, M.: Somatostatin immunoreactive senile plaque-like structures in the frontal cortex and nucleus accumbens of aged tree shrews and Japanese macaques, J. Med. Primatol., 41, 147-157, 2012.

Zhao, X., Tang, Z. Y., Klumpp, B., Wolff-Vorbeck, G., Barth, H., Levy, S., von Weizsäcker, F., Blum, H. E., and Baumert, T. F.: Primary hepatocytes of Tupaia belangeri as a potential model for hepatitis C virus infection, J. Clin. Invest., 109, 221-232, 2002. 